\title{
FREQUÊNCIA, INTENSIDADE E VARIABILIDADE PLUVIOMÉTRICA NA MESORREGIÃO SUDOESTE PARANAENSE
}

\author{
CALDANA, Nathan Felipe da Silva - nathancaldana@gmail.com \\ Universidade Tecnólogica Federal do Paraná / UTFPR \\ MARTELÓCIO, Alan Carlos - amartelocio@agronomo.eng.br \\ Instituto Agronômico do Paraná / IAPAR \\ RUDKE, Anderson Paulo - rudke@alunos.utfpr.edu.br \\ Universidade Federal de Minas Gerais / UFMG \\ NITSCHE, Pablo Ricardo - pablo@iapar.br \\ Instituto Agronômico do Paraná / IAPAR \\ CARAMORI, Paulo Henrique - pcaramori@gmail.com \\ Instituto Agronômico do Paraná / IAPAR
}

\begin{abstract}
RESUMO: Os eventos extremos de precipitação causam danos severos tanto no espaço urbano quanto no rural. O aumento da temperatura média da superfície global, em conjunto com eventos extremos de precipitação causam grandes incertezas na dinâmica dos impactos das condições de tempo e clima, e como se planejar para prevenir os impactos é um tema que se torna cada vez mais crucial. Dessa forma, estudos que evidenciem a variabilidade climática em diferentes escalas são fundamentais para o planejamento das atividades humanas. O estado do Paraná se encontra em uma região de transição climática com grande variação dos elementos meteorológicos, sendo essencial a compreensão desses fenômenos devido a seus possíveis impactos. Nesse sentido, o objetivo desse trabalho foi analisar a variabilidade pluviométrica, a intensidade e frequência da precipitação na Mesorregião Sudoeste Paranaense - MRSPR associados ao fenômeno El Niño Oscilação Sul - ENOS. Para isso utilizou-se as escalas temporais anual, mensal e diária com o recorte temporal de 1976 a 2017. Através dos resultados, identificou-se grande discrepância nas alturas pluviométricas anuais, mensais e diárias, com parte expressiva dos eventos extremos e maiores alturas de precipitação ocorrendo em períodos de El Niño, enquanto os períodos secos predominam em condições de La Niña.
\end{abstract}

PALAVRAS-CHAVES: risco climático, eventos extremos, temperatura da superfície do mar; El Niño-Oscilação Sul.

\section{FREQUENCY, INTENSITY AND PLUVIOMETRIC VARIABILITY IN THE SOUTHEAST PARANAENSE MESOREGION}

ABSTRACT: Extreme precipitation events cause severe damage in both urban and rural areas. The increase in average global surface temperature together with extreme precipitation events causes great uncertainties in the dynamics of the impacts of weather and climate conditions, and how planning to prevent impacts is an increasingly crucial issue. Thus, studies that show the climatic variability at different scales are fundamental for the planning of human activities. The state of Paraná is located in a climatic transition region with great variation of the meteorological elements and their impacts. The objective of this work was to analyze the rainfall variability, the intensity and the frequency of precipitation in the Southwest Meso-region of Paraná - MRSPR associated with the EI Niño Southern Oscillation - ENOS phenomenon. For this purpose, the annual, monthly and daily time scales were used with the temporal range from 1976 to 2017. A great discrepancy was identified in annual, monthly and daily rainfall heights, with an expressive part of extreme events and higher precipitation occurring in periods of $\mathrm{El}$ Niño, while dry periods predominate under La Niña conditions. 
KEYWORDS: climate risk, natural disasters; sea surface temperature; El Niño- Southern Oscillation.

\section{INTRODUÇÃO}

A variabilidade climática compreende tanto as escalas do espaço quanto do tempo. O seu ritmo nunca é igual de um ano para o outro e nem de década para década. As flutuações variam a curto, médio e longo prazo e, neste caso, o clima é resultado de um processo complexo que envolve a energia solar, dinâmica da atmosfera, oceano, cobertura e temperatura das superfícies, albedo, dentre outros elementos e fatores. Soma-se a isso, o aumento de temperatura média da superfície global em conjunto com os eventos extremos de precipitação incidentes sobre diversas partes do mundo, sendo salientado no The Fifth Assessment Report - AR5 que essas ocorrências se tornarão muito mais frequentes durante todo o século XXI. Esses eventos causam impacto direto ao se pensar na dinâmica da sociedade/natureza (CONTI, 2005; IPCC, 2013; SANCHES et al., 2014; KARIMI et al., 2017; KARIMI et al., 2018; SOMBOONSUKE, 2018; PAILLER; TSANEVA, 2018).

Apesar dos recentes avanços tecnológicos e científicos, o clima ainda é a variável mais importante na produção agrícola. As variáveis naturais mais significativas no processo produtivo são provenientes do clima, independentemente do modo de produção, aos quais são consideradas insumos e energia no sistema terrestre. Na agricultura, a variabilidade da produção é afetada em até $80 \%$ pelas condições meteorológicas. A precipitação pluviométrica é o elemento mais importante e o atributo climático de maior expressão e significância nas regiões de clima tropical e subtropical, onde a sua distribuição variável anualmente e períodos de chuva extrema e seca influenciam nas diversas atividades humanas (AYOADE, 1986; PELL et al., 2007; CARAMORI et al., 2008; AGOVINO et al., 2018; GELCER et al., 2018; MICHLER et al., 2018).

A Mesorregião Sudoeste Paranaense (MRSPR) conta com mais de 500 mil habitantes (IBGE, 2018) e tem grande parte da sua área destinada à agropecuária. Trabalhos que identifiquem e prevejam períodos de seca, chuva intensa, vendavais, granizo e geadas contribuem para um melhor planejamento, manejo de culturas e tomadas de decisão, visando uma melhor forma de se obter bons resultados e menores danos ambientais com essa atividade econômica. Diversos trabalhos são realizados em todo o mundo demonstrando a importância do regime de chuvas para as mais distintas produções e para o zoneamento e planejamento do calendário agrícola (MANCILLAS et al., 2015; CARVALHO et al., 2017; DAMASCENA et al., 2017; MACHADO et al., 2017; PANDOLFO et al., 2017; PASSOS et al., 2017; DOS REIS et al., 2017; ALBUQUERQUE et al., 2018; CONCEIÇÃO et al., 2018; GELCER et al., 2018; DE MATOS et al., 2018; MEDEIROS et al., 2018; SANTI et al., 2018; DE SOUSA e DE OLIVEIRA, 2018; DE SOUZA et al., 2018; TAYT'SOHN et al., 2018).

Para áreas urbanas os desastres naturais ocorrem como consequência dos episódios extremos de precipitação. A inundação é a principal causa de eventos extremos do clima, com 59\% dos registros (MARCELINO, 2007). As instabilidades atmosféricas severas geram grandes volumes de chuva em pouco tempo, e junto a isso, a baixa drenagem dos espaços urbanos e a ocupação de áreas inadequadas são os responsáveis por tais eventos. Trabalhos que identifiquem a frequência e intensidade desses eventos extremos auxiliam na 
tomada de decisão e no planejamento urbano regional (BERTILSSON et al., 2018; HUANG et al., 2018; JAMALI et al., 2018; MUSTAFA et al., 2018).

Dessa forma, o objetivo do presente trabalho foi analisar a variabilidade pluviométrica e a intensidade e frequência da precipitação na MRSPR, bem como avaliar a associação entre os totais de pluviosidade e extremos com a ocorrência do modo de variabilidade El Niño Oscilação Sul - ENOS. Para isso, utilizou-se as escalas temporais anual, sazonal, mensal e diária com o recorte temporal de 1976 a 2017.

\section{MATERIAL E MÉTODOS}

Foram utilizados dados de 32 estações pluviométricas do Instituto Agronômico do Paraná (IAPAR), Instituto Nacional de Meteorologia (INMET), Agência Nacional das Águas (ANA) e Instituto das Águas do Paraná (Figura 01).

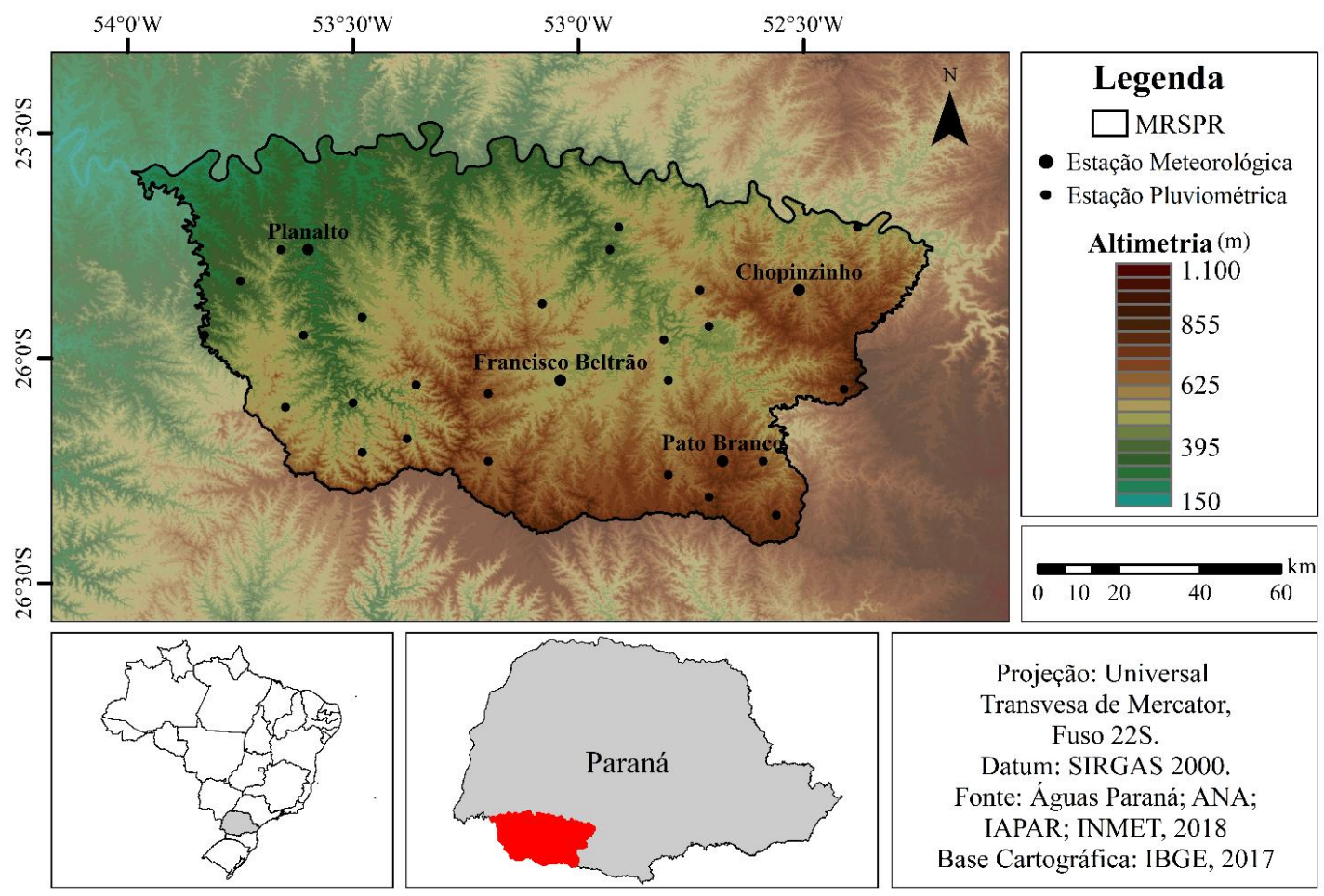

Figura 01 - Localização das estações pluviométricas e o relevo da Mesorregião Sudoeste Paranaense. Fonte: IBGE (2018); organizado pelos autores.

As matrizes de precipitação foram geradas a partir dos dados pontuais das estações pluviométricas com o auxílio do Software Qgis utilizando o interpolador IDW (Inverse distance weighted), com resolução espacial de $1 \mathrm{~km}$. Dessa forma, os dados foram inseridos e transformados em um arquivo tipo raster, com o auxílio do interpolador IDW. Este novo arquivo exibe uma superfície regular ajustada a estes dados pontuais de interesse e, posteriormente foram inseridas isoietas e seus valores para melhor visualização das áreas com precipitação similar. 
Além disso, para auxiliar na apresentação da distribuição de frequência dos dados em estudo foram utilizados os gráficos no formato de Box Plot. Por meio destes gráficos, é possível analisar: a medida de suas dispersões ao entorno da média por meio do desvio padrão, a posição de sua mediana, a que demonstra onde se encontra $50 \%$ dos dados, sua assimetria e a presença de pontos discrepantes ou outliers e extremos (LEM et al., 2013; SCHNEIDER e DA SILVA, 2014).

Para a análise da variabilidade pluviométrica foram utilizados os gráficos de Box Plot. Estes representam cinco classificações de valores, são eles: mediana, outliers discrepantes e extremos e valores máximos e mínimos. Dentro box plot são classificados três quartis (Q) com $25 \%$ dos dados cada, além do valor da mediana, que equivale ao segundo quartil - $50 \%$ dos dados (LEM et al., 2013; SCHNEIDER e DA SILVA, 2014). Os outliers são divididos em discrepantes (valores acima do considerado máximo, mas que não são extremos) e extremos, sendo considerados quaisquer valores superiores a Q3 + 1,5 (Q3 - Q1) ou inferiores a Q1 - 1,5 (Q3 - Q1). Os máximos e mínimos são considerados os maiores valores da série, mas que não são extremos ou discrepantes.

Para a análise por meio de Box Plot, foram utilizados dados de quatro estações meteorológicas, sendo uma em cada extremo da região e com discrepâncias nas alturas pluviométricas. Dessa forma, utilizou-se as estações de Chopinzinho, Francisco Beltrão, Pato Branco e Planalto (Figura 02). As escalas temporais analisadas por meio do box plot foram anuais e mensais para as alturas pluviométricas e número de dias com chuva. Os gráficos foram tabulados e editados nos softwares Sigmaplot e Statistica.

Os dados de variabilidade climática ENOS foram obtidos na base de dados de Oceanic Niño Index (ONI), divulgados pelo Climate Prediction Center da National Oceanic Atmosphere Administration (NOAA, 2019), com o intuito de comparar a ocorrência de anos secos, chuvosos e os eventos extremos com a incidência dos eventos de El Niño e La Niña, dessa forma buscou-se apenas identificar o padrão do ENOS na ocorrência desses eventos, descartando a análise do seu meio de formação. O ONI é classificado por média móvel trimestral para determinar a Temperatura da Superfície do Mar (TSM) do Pacífico Equatorial, na região El Niño 3.4 para cada mês (TRENBERTH et al., 2019). Para caracterizar El Niño, é necessário que ocorram pelo menos cinco trimestres móveis com a TSM com desvio igual ou superior a $0,5^{\circ} \mathrm{C}$ acima da média histórica. O La Niña se estabelece quando as temperaturas médias permanecem inferiores a $-0,5^{\circ} \mathrm{C}$ por pelo menos cinco trimestres móveis, enquanto os valores intermediários são classificados como neutros ou normalidade (Tabela 01). O recorte temporal analisado foi de 1976 a 2017. 
Quadro 01 - Anos e meses de ocorrência do ENOS (El Niño em vermelho, La Niña em azul, e Normalidade em preto) entre 1976-2017.

\begin{tabular}{|c|c|c|c|c|c|c|c|c|c|c|c|c|}
\hline & $\mathrm{DJF}$ & $\begin{array}{l}\mathbf{J F} \\
\mathrm{M}\end{array}$ & $\begin{array}{c}\text { FM } \\
\text { A }\end{array}$ & MAM & AMJ & $M J J$ & JJA & JAS & $\begin{array}{c}\text { AS } \\
0\end{array}$ & $\begin{array}{c}\text { SO } \\
\mathrm{N}\end{array}$ & $\begin{array}{c}\text { ON } \\
\text { D }\end{array}$ & NDJ \\
\hline 1976 & ${ }_{1,5}^{-}$ & ${ }_{1,1}^{-}$ & $-0,7$ & $-0,4$ & $-0,3$ & $-0,1$ & 0,1 & 0,3 & 0,5 & 0,7 & 0,8 & 0,8 \\
\hline 1977 & 0,7 & 0,6 & 0,4 & 0,3 & 0,3 & 0,4 & 0,4 & 0,4 & 0,5 & 0,6 & 0,8 & 0,8 \\
\hline 1978 & 0,7 & 0,4 & 0,1 & $-0,2$ & $-0,3$ & $-0,3$ & $-0,4$ & $-0,4$ & 0,4 & $-0,3$ & $-0,1$ & 0 \\
\hline 1979 & 0 & 0,1 & 0,2 & 0,3 & 0,3 & 0,1 & 0,1 & 0,2 & 0,3 & 0,5 & 0,5 & 0,6 \\
\hline 1980 & 0,6 & 0,5 & 0,3 & 0,4 & 0,5 & 0,5 & 0,3 & 0,2 & 0 & 0,1 & 0,1 & 0 \\
\hline 1981 & $\overline{0}, \overline{2}$ & $\begin{array}{c}- \\
0,4\end{array}$ & $-0,4$ & $-0,3$ & $-0,2$ & $-0,3$ & $-0,3$ & $-0,3$ & $0,-$ & $-0,1$ & $-0,1$ & 0 \\
\hline 1982 & 0 & 0,1 & 0,2 & 0,5 & 0,6 & 0,7 & 0,8 & 1,0 & 1,5 & 1,9 & 2,1 & 2,1 \\
\hline 1983 & 2,1 & 1,8 & 1,5 & 1,2 & 1,0 & 0,7 & 0,3 & 0 & $\begin{array}{c}- \\
0,3\end{array}$ & $-0,6$ & $-0,8$ & $-0,8$ \\
\hline 1984 & $\begin{array}{c}- \\
0,5\end{array}$ & $\overline{0}, 3$ & $-0,3$ & $-0,4$ & $-0,4$ & $-0,4$ & $-0,3$ & $-0,2$ & 0,3 & $-0,6$ & $-0,9$ & $-1,1$ \\
\hline 1985 & $\begin{array}{c}- \\
0,9\end{array}$ & $\begin{array}{c}- \\
0,7\end{array}$ & $-0,7$ & $-0,7$ & $-0,7$ & $-0,6$ & $-0,4$ & $-0,4$ & - & $-0,3$ & $-0,2$ & $-0,3$ \\
\hline 1986 & - & - & $-0,3$ & $-0,2$ & $-0,1$ & 0 & 0,2 & 0,4 & 0,7 & 0,9 & 1,0 & 1,1 \\
\hline 1987 & 1,1 & 1,2 & 1,1 & 1,0 & 0,9 & 1,1 & 1,4 & 1,6 & 1,6 & 1,4 & 1,2 & 1,1 \\
\hline 1988 & 0,8 & 0,5 & 0,1 & $-0,3$ & $-0,8$ & $-1,2$ & $-1,2$ & $-1,1$ & $\begin{array}{c}- \\
1,2\end{array}$ & $-1,4$ & $-1,7$ & $-1,8$ \\
\hline 1989 & $\begin{array}{c}- \\
1,6 \\
\end{array}$ & $\begin{array}{c}- \\
1,4 \\
\end{array}$ & $-1,1$ & $-0,9$ & $-0,6$ & $-0,4$ & $-0,3$ & $-0,3$ & - & $-0,3$ & $-0,2$ & $-0,1$ \\
\hline 1990 & 0,1 & 0,2 & 0,2 & 0,2 & 0,2 & 0,3 & 0,3 & 0,3 & 0,4 & 0,3 & 0,4 & 0,4 \\
\hline 1991 & 0,4 & 0,3 & 0,2 & 0,2 & 0,4 & 0,6 & 0,7 & 0,7 & 0,7 & 0,8 & 1,2 & 1,4 \\
\hline 1992 & 1,6 & 1,5 & 1,4 & 1,2 & 1,0 & 0,8 & 0,5 & 0,2 & 0 & $-0,1$ & $-0,1$ & 0 \\
\hline 1993 & 0,2 & 0,3 & 0,5 & 0,7 & 0,8 & 0,6 & 0,3 & 0,2 & 0,2 & 0,2 & 0,1 & 0,1 \\
\hline 1994 & 0,1 & 0,1 & 0,2 & 0,3 & 0,4 & 0,4 & 0,4 & 0,4 & 0,4 & 0,6 & 0,9 & 1,0 \\
\hline 1995 & 0,9 & 0,7 & 0,5 & 0,3 & 0,2 & 0 & $-0,2$ & $-0,5$ & $\begin{array}{c}- \\
0,7\end{array}$ & $-0,9$ & $-1,0$ & $-0,9$ \\
\hline 1996 & $\begin{array}{c}- \\
0,9\end{array}$ & $\begin{array}{c}- \\
0,7\end{array}$ & $-0,6$ & $-0,4$ & $-0,2$ & $-0,2$ & $-0,2$ & $-0,3$ & - & $-0,4$ & $-0,4$ & $-0,5$ \\
\hline 1997 & $\begin{array}{c}- \\
0,5\end{array}$ & $\begin{array}{c}- \\
0,4\end{array}$ & $-0,2$ & 0,1 & 0,6 & 1,0 & 1,4 & 1,7 & 2,0 & 2,2 & 2,3 & 2,3 \\
\hline 1998 & 2,1 & 1,8 & 1,4 & 1,0 & 0,5 & $-0,1$ & $-0,7$ & $-1,0$ & ${ }_{1,2}^{-}$ & $-1,2$ & $-1,3$ & $-1,4$ \\
\hline 1999 & $\begin{array}{c}- \\
1,4\end{array}$ & $\begin{array}{c}- \\
1,2 \\
\end{array}$ & $-1,0$ & $-0,9$ & $-0,9$ & $-1,0$ & $-1,0$ & $-1,0$ & $\begin{array}{c}- \\
1,1\end{array}$ & $-1,2$ & $-1,4$ & $-1,6$ \\
\hline 2000 & $\begin{array}{c}- \\
1,6\end{array}$ & $\begin{array}{c}- \\
1,4\end{array}$ & $-1,1$ & $-0,9$ & $-0,7$ & $-0,7$ & $-0,6$ & $-0,5$ & $\begin{array}{c}- \\
0,6\end{array}$ & $-0,7$ & $-0,8$ & $-0,8$ \\
\hline 2001 & $\begin{array}{c}- \\
0,7 \\
\end{array}$ & $\begin{array}{c}- \\
0,5 \\
\end{array}$ & $-0,4$ & $-0,3$ & $-0,2$ & $-0,1$ & $-0,1$ & $-0,1$ & $\begin{array}{c}- \\
0,2\end{array}$ & $-0,3$ & $-0,4$ & $-0,3$ \\
\hline 2002 & - & 0,0 & 0,1 & 0,2 & 0,4 & 0,6 & 0,8 & 0,8 & 0,9 & 1,1 & 1,2 & 1,1 \\
\hline 2003 & 0,9 & 0,7 & 0,4 & 0 & $-0,2$ & $-0,1$ & 0,1 & 0,2 & 0,2 & 0,3 & 0,3 & 0,3 \\
\hline 2004 & 0,3 & 0,3 & 0,2 & 0,1 & 0,2 & 0,3 & 0,5 & 0,6 & 0,7 & 0,7 & 0,6 & 0,7 \\
\hline 2005 & 0,7 & 0,6 & 0,5 & 0,5 & 0,3 & 0,2 & 0 & $-0,1$ & 0 & $-0,2$ & $-0,5$ & $-0,7$ \\
\hline 2006 & $\begin{array}{c}- \\
0,7\end{array}$ & - & $-0,4$ & $-0,2$ & 0,0 & 0,0 & 0,1 & 0,3 & 0,5 & 0,7 & 0,9 & 0,9 \\
\hline 2007 & 0,7 & 0,4 & 0,1 & $-0,1$ & $-0,2$ & $-0,3$ & $-0,4$ & $-0,6$ & $\begin{array}{c}- \\
0,9 \\
\end{array}$ & $-1,1$ & $-1,3$ & $-1,3$ \\
\hline
\end{tabular}




\begin{tabular}{|c|c|c|c|c|c|c|c|c|c|c|c|c|}
\hline 2008 & $\begin{array}{c}- \\
1,4\end{array}$ & $\begin{array}{c}- \\
1,3\end{array}$ & $-1,1$ & $-0,9$ & $-0,7$ & $-0,5$ & $-0,4$ & $-0,3$ & $\begin{array}{c}- \\
0,3\end{array}$ & $-0,4$ & $-0,6$ & $-0,7$ \\
\hline 2009 & $\begin{array}{c}- \\
0,7 \\
\end{array}$ & $\begin{array}{c}- \\
0,6 \\
\end{array}$ & $-0,4$ & $-0,1$ & 0,2 & 0,4 & 0,5 & 0,5 & 0,6 & 0,9 & 1,1 & 1,3 \\
\hline 2010 & 1,3 & 1,2 & 0,9 & 0,5 & 0,0 & $-0,4$ & $-0,9$ & $-1,2$ & $\begin{array}{c}- \\
1,4\end{array}$ & $-1,5$ & $-1,4$ & $-1,4$ \\
\hline 2011 & $\begin{array}{c}- \\
1,3\end{array}$ & $\begin{array}{c}- \\
1,0\end{array}$ & $-0,7$ & $-0,5$ & $-0,4$ & $-0,3$ & $-0,3$ & $-0,6$ & $-\overline{0}$ & $-0,9$ & $-1,0$ & $-0,9$ \\
\hline 2012 & $\begin{array}{c}- \\
0,7\end{array}$ & $\begin{array}{c}- \\
0,5\end{array}$ & $-0,4$ & $-0,4$ & $-0,3$ & $-0,1$ & 0,1 & 0,3 & 0,3 & 0,3 & 0,1 & $-0,2$ \\
\hline 2013 & - & $\begin{array}{c}- \\
0,4\end{array}$ & $-0,3$ & $-0,2$ & $-0,2$ & $-0,2$ & $-0,3$ & $-0,3$ & $\begin{array}{c}- \\
0,2\end{array}$ & $-0,3$ & $-0,3$ & $-0,3$ \\
\hline 2014 & $\begin{array}{c}- \\
0,5\end{array}$ & $\overline{-}, 5$ & $-0,4$ & $-0,2$ & $-0,1$ & 0,0 & $-0,1$ & 0,0 & 0,1 & 0,4 & 0,5 & 0,6 \\
\hline 2015 & 0,6 & 0,5 & 0,6 & 0,7 & 0,8 & 1,0 & 1,2 & 1,4 & 1,7 & 2,0 & 2,2 & 2,3 \\
\hline 2016 & 2,5 & 2,2 & 1,7 & 1 & 0,5 & 0 & $-0,3$ & $-0,6$ & $\begin{array}{c}- \\
0,7 \\
\end{array}$ & $-0,7$ & $-0,7$ & $-0,6$ \\
\hline 2017 & $\begin{array}{c}- \\
0,3\end{array}$ & $\begin{array}{c}- \\
0,1\end{array}$ & 0,1 & 0,3 & 0,4 & 0,4 & 0,2 & $-0,1$ & ${ }^{-}, 4$ & $-0,7$ & $-0,9$ & -1 \\
\hline
\end{tabular}

Fonte: NOAA/CPC (2016); adaptado pelos autores.

\section{RESULTADOS}

A precipitação pluviométrica anual apresenta grande variabilidade na MRSPR (figura 02). A porção Norte, próximo ao rio Iguaçu (menores altitudes da região - 200 a $600 \mathrm{~m}$ ), apresenta as menores alturas pluviométricas, oscilando de 1980 a 2060mm. Enquanto a porção mais alta (500 a 900m) ao sul apresenta as maiores alturas pluviométricas médias, variando de 2040 a $2120 \mathrm{~mm}$. As exceções ocorrem nas porções extremo nordeste e sudeste da região, com altitude de aproximadamente $800 \mathrm{~m}$ e precipitação de 2000 e 2040mm, respectivamente. 


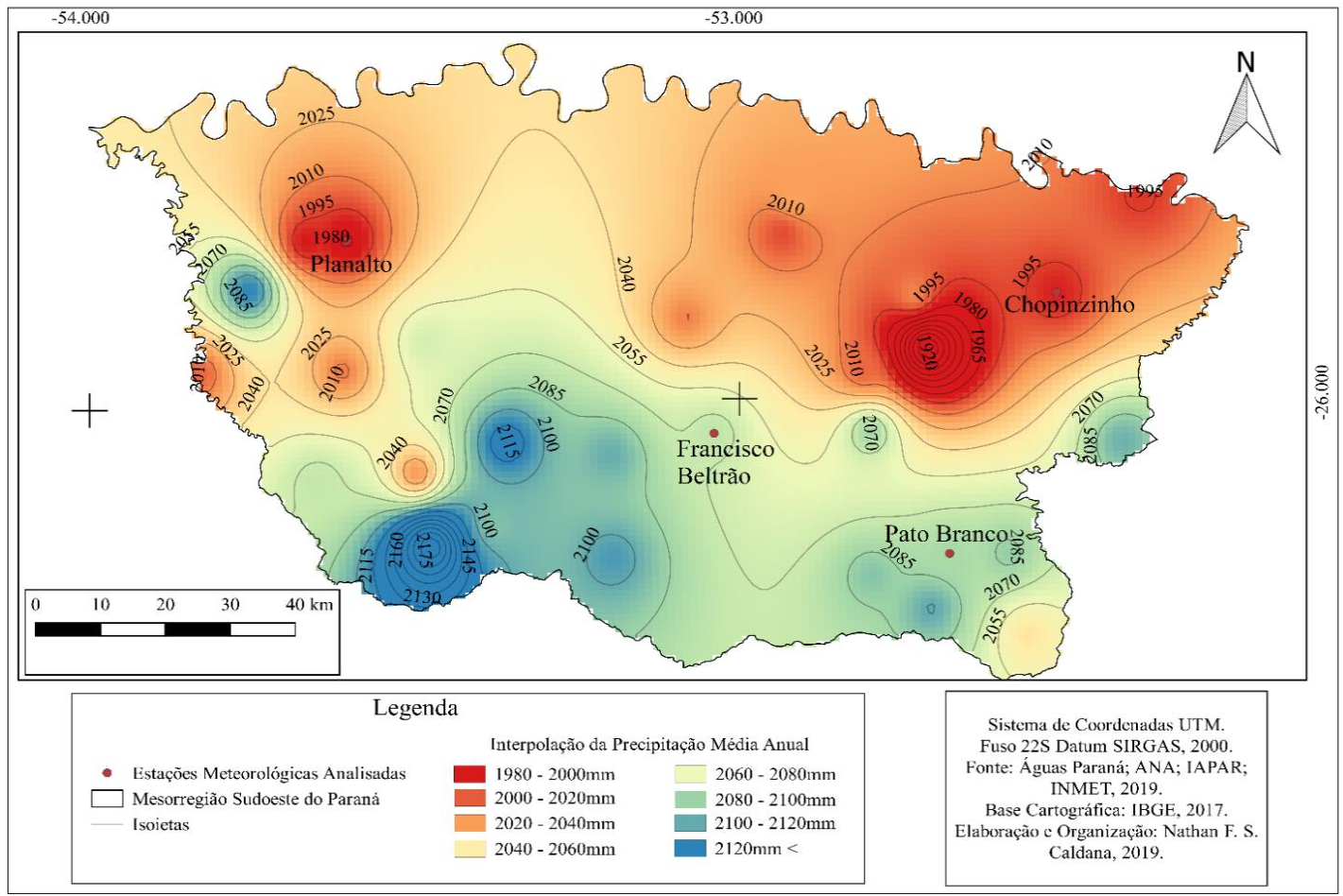

Figura 02 - Precipitação Média Anual na Mesorregião Sudoeste Paranaense. Fonte dos dados: Águas Paraná; ANA; IAPAR e INMET (2019), organizado pelos autores (2019).

A região possui três principais sistemas atmosféricos (Frente Fria, Sistema Convectivo e Complexo Convectivo de Mesoescala) responsáveis pela formação e distribuição da precipitação. Primeiro as frentes frias, que são caracterizadas pelo encontro da Massa de Ar Polar com a massa de ar quente continental; com o advento da umidade geram uma forte instabilidade atmosférica, podendo levar à formação de cumulunimbus e acarretar na formação de tempestades severas, podendo vir acompanhada de fortes rajadas de vento e de precipitação de granizo, ou ainda de chuva de intensidade fraca a moderada, mas com duração de dias, se essa vier a ser estacionária. Essas têm atuação, principalmente, no outono, inverno e início da primavera e são responsáveis pelas elevadas alturas pluviométricas na região, segunda mais chuvosa do Estado, sendo suplantada apenas pelo litoral (IAPAR, 2019). A Massa de Ar Polar tem trajetória favorecida pela calha do Rio Paraná e posteriormente Rio Iguaçu, tendo grande impacto na chuva da região. São identificados em imagens de satélite por uma grande linha de instabilidade que avança no estado do Paraná no sentido Sudoeste - Nordeste. E como observado, o relevo na porção sul da região possui rápida ascensão, de 200 a $900 \mathrm{~m}$; esse choque com o relevo pode trazer mais chuva na porção mais alta da região, próximo à divisa com Santa Catarina (HOLLEMAN, 2001; BEREZUK e SANT'ANNA NETO, 2006; KUNZ et al., 2009; BEREZUK, 2017; PUNGE et al., 2017; SANCHEZ et al., 2017; CALDANA et al., 2018a; CALDANA et al., 2018b).

Os outros dois principais meios de formação de precipitação na região são os Sistemas Convectivos e os Complexos Convectivos de Mesoescala - CCM, que têm atuação durante todo o ano, mas com predomínio nas estações de 
primavera e verão. Os CCM são identificados em imagens de satélite pelo seu formato aproximadamente circular e por uma vasta área de abrangência de tempestades. São definidos como um aglomerado de cumulunimbus cobertos por uma densa camada de cirros, sendo ainda sistemas de nuvens convectivas, com rápido crescimento vertical e horizontal num intervalo de tempo de 6 a 12 horas. Dependendo de sua intensidade, podem criar vários núcleos com formação de tempestades e incidência de granizo. Seu deslocamento pelo Paraná é, normalmente, no sentido Oeste - Leste, advindos do Paraguai (HOLLEMAN, 2001; SCAGLIONI e SARAIVA, 2004; KUNZ et al., 2009; PUNGE e KUNZ, 2016; DAFIS et al., 2017; PUNGE et al., 2017; TREFAULT et al., 2018; CALDANA et al., 2018a; CALDANA et al., 2018b).

Os sistemas convectivos se diferenciam dos CCM pela menor abrangência espacial, formando-se pelo processo de transferência de calor por condução que ocorre em intensos movimentos verticais, levando assim ao rápido processo de condensação e a formação de Cumulunimbus. Em ambos sistemas, o atrito com o relevo também pode contribuir para a ascensão do ar mais quente e úmido, podendo formar núcleos de condensação e chuva. Isto explica as maiores alturas pluviométricas médias nas porções mais elevadas da região (HOLLEMAN, 2001; MIDDLETON e MCWATERS, 2002; SCAGLIONI e SARAIVA, 2004; KUNZ et al., 2009; DAFIS et al., 2017; TREFAULT et al., 2018; CALDANA et al., 2018a).

Para melhor compreender a distribuição pluviométrica foram utilizados gráficos de box plot para algumas estações com precipitações discrepantes na região (Figura 03). Observa-se que as quatro estações apresentaram valores outliers, com grande diferença entre os valores máximo e mínimo e pequena diferença entre as medianas das estações. 


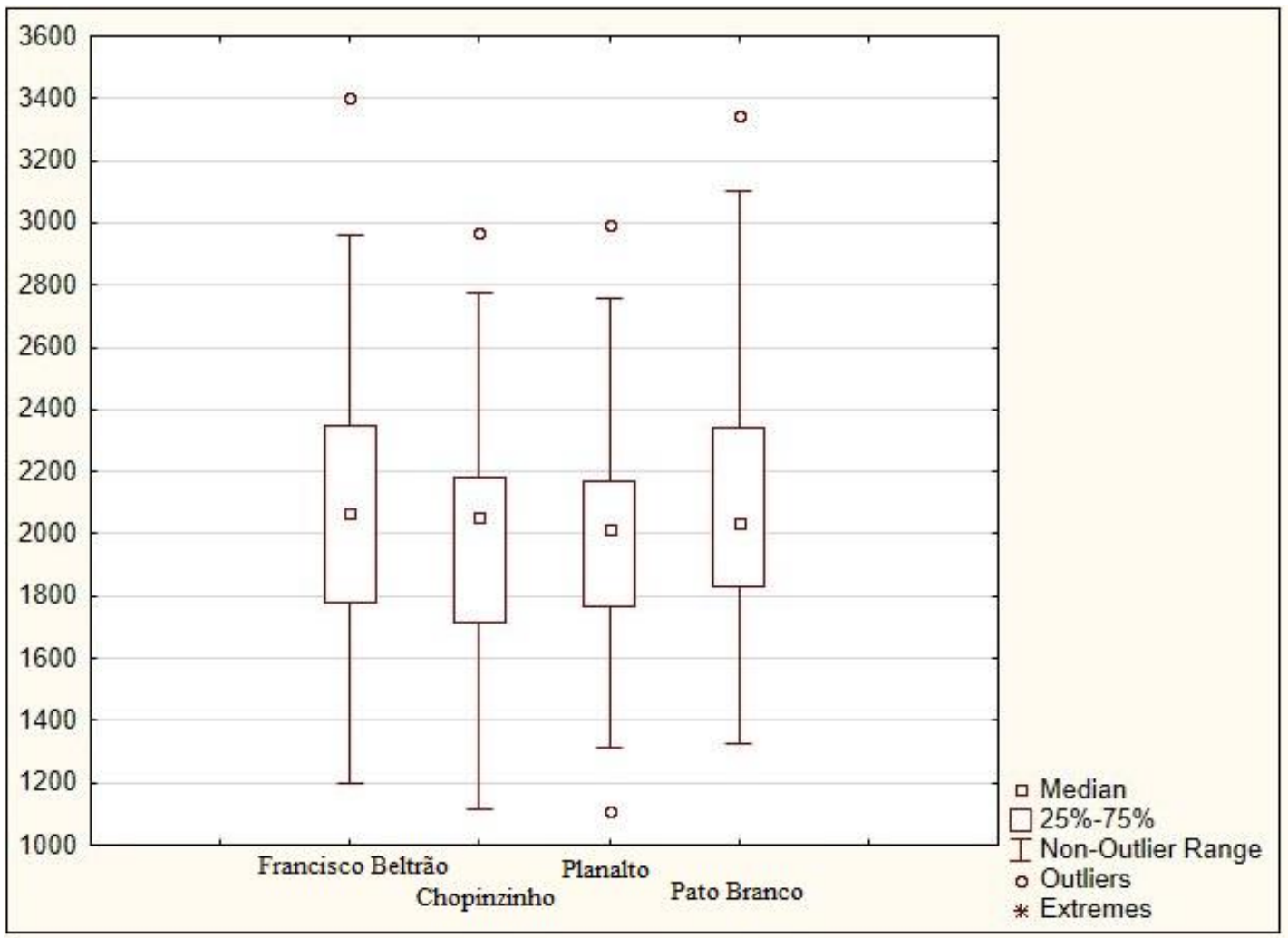

Figura 03 - Variabilidade da Precipitação Pluviométrica Anual na Mesorregião Sudoeste Paranaense. Fonte dos dados: Águas Paraná; ANA; IAPAR e INMET (2019), organizado pelos autores (2019).

Na estação de Planalto, no extremo oeste da região, observou-se as menores alturas pluviométricas anuais, havendo um valor discrepante na parte superior do box plot, referente ao ano de 1983 com altura pluviométrica de $2990 \mathrm{~mm}$. Cabe ressaltar, que nesse ano houve influência de um El Niño. Enquanto, na parte inferior do box plot houve outro valor discrepante referente ao ano de $1985 \mathrm{com} 1111 \mathrm{~mm}$, quando houve a influência do fenômeno La Niña. A mediana dessa estação foi de $2002 \mathrm{~mm}$.

Já a estação de Pato Branco apresentou mediana de $2221 \mathrm{~mm}$ e um valor discrepante no ano de 1983, com $3101 \mathrm{~mm}$, a segunda maior altura pluviométrica anual dentre as estações. Enquanto para a estação de Chopinzinho observou-se mediana de $2242 \mathrm{~mm}$ e um valor discrepante também no ano de 1983. Nessa estação ainda se constatou o box plot mais assimétrico dentre as estações analisadas.

A estação de Francisco Beltrão apresentou as maiores alturas pluviométricas dentre as estações analisadas. $O$ único valor discrepante observado nesta estação é a maior altura pluviométrica da série, com $3405 \mathrm{~mm}$, também no ano de 1983. Foi a estação que apresentou maior diferença entre quartis, com o Q1 de $1791 \mathrm{~mm}$ e o Q3 de $2369 \mathrm{~mm}$.

Observou-se que, divergindo dos totais de chuva anual, a estação de Pato Branco registrou o maior número de dias com chuva (Figura 04) dentre as 
estações analisadas, com mediana de 136 dias. Um fator que pode justificar este padrão é a altitude da estação, uma vez que é a maior dentre as analisadas, com 700m, sendo que, possui $400 \mathrm{~m}$ de elevação numa curta distância antes da divisa com o estado de Santa Catarina. Enquanto as demais têm 400m em Planalto, 650m em Francisco Beltrão e 692m Chopinzinho, sendo que todas essas possuem redução na altitude no sentido Sul-Norte (Figura 01), sentido pelo qual se deslocam as massas de ar. Em Pato Branco o ano de 1990 foi o que apresentou mais dias com chuva em condições de neutralidade do fenômeno ENOS - 174 dias. Em condições de neutralidade do ENOS podem ocorrer períodos de precipitação elevada na região Sul do Brasil, pois há redução nos bloqueios atmosféricos na faixa subtropical, enquanto na faixa tropical da América do Sul o ar que ascende a oeste (baixa pressão atmosférica) tende a descer sobre as águas frias a leste (alta pressão atmosférica). Em consequência, tem-se ausência de nuvens e de precipitação nesta região (RAO e HADA, 1997; FONTANA e BERLATO, 1997; PODESTA et al., 2002; BERLATO, 2005; BERLATO e FONTANA, 2011; ANDERSON et al., 2017). Fator que justifica as precipitações elevadas em todas as análises para o período de neutralidade na região.

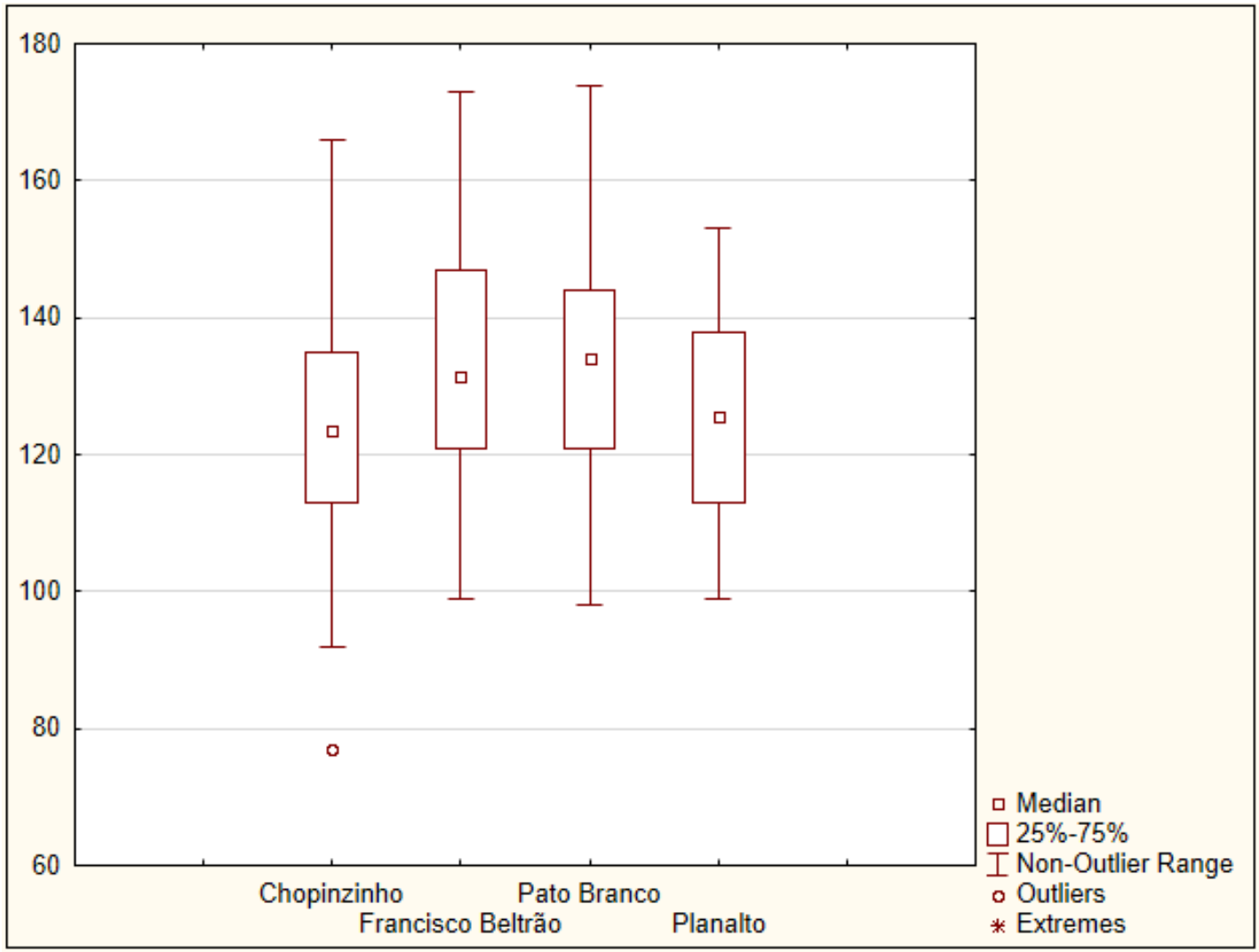

Figura 04 - Variabilidade do número de dias com chuva na Mesorregião Sudoeste Paranaense. Fonte dos dados: Águas Paraná; ANA; IAPAR e INMET (2019), organizado pelos autores (2019). 
Cabe-se destacar que 1990 não foi o ano mais chuvoso da série, ficando atrás de 1983 com 163 dias com chuva, mostrando que houve maior concentração de chuva em menos dias neste ano. Dessa forma, identificou-se por meio do número de dias com chuva que a precipitação nesta estação é mais frequente, porém com menor intensidade que nas demais.

A estação de Francisco Beltrão apresentou mediana de 133 dias com chuva, variando de 173 a 99 dias. O ano com maior registro de dias com chuva foi 1990, mesmo não sendo o ano mais chuvoso, e o menor registro foi em 1978, ambos em período de normalidade da TSM. Por ser a estação com maiores alturas pluviométricas, observou-se que nesta estação a precipitação é menos frequente, porém com maior intensidade.

A estação de Planalto foi a que apresentou menor discrepância no número de dias com chuva anual, com variação de 99 a 153 dias, nos anos de 1991 e 1990, respectivamente. A mediana desta estação foi de 124 dias com chuva, a terceira dentre as analisadas, superando assim Chopinzinho, mesmo tendo alturas pluviométricas anuais inferiores (Figura 02).

Chopinzinho foi a estação com menor mediana de número de dias com chuva, com 122 dias. Nesta estação observou-se um valor discrepante, na parte interior do box plot, de 77 dias com chuva no ano de 1978, em período de normalidade da TSM.

Mensalmente (Figura 05), as estações demostraram distribuição da precipitação similar à anual, com as maiores alturas pluviométricas observadas na estação de Francisco Beltrão e as menores em Planalto.

Na estação de Planalto, observou-se um valor extremo no mês de maio de 1983 , com precipitação de $485.3 \mathrm{~mm}$, referente a um período de El Niño forte. Foram observados ainda 10 valores discrepantes na série analisada. 0 mês mais chuvoso na estação foi outubro, com mediana de $225 \mathrm{~mm}$, enquanto o mais seco foi agosto, com mediana de $85 \mathrm{~mm}$. O mês mais seco observado na série da estação foi em julho de 1981 , com altura pluviométrica de $1.3 \mathrm{~mm}$, observado em período de TSM com anomalia negativa, porém, em período de neutralidade. Em seguida, observou-se duas ocorrências de precipitação com $1.6 \mathrm{~mm}$ em abril de 1978 e maio de 2006, também em período de normalidade do ENOS. 


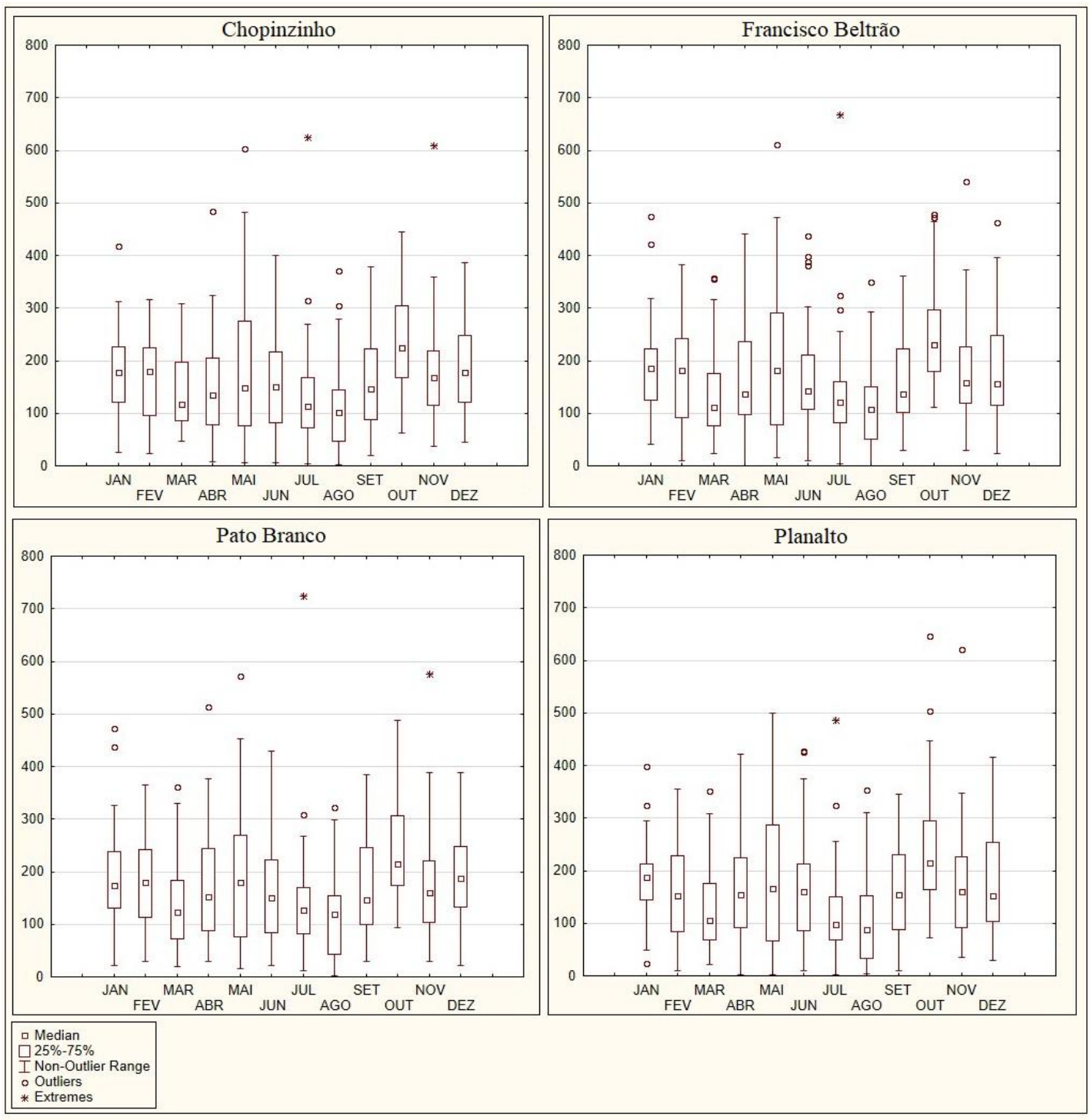

Figura 05 - Variabilidade da Precipitação Pluviométrica Mensal na Mesorregião Sudoeste Paranaense. Fonte dos dados: Águas Paraná; ANA; IAPAR e INMET (2019), organizado pelos autores (2019).

Na estação de Chopinzinho observou-se seis valores discrepantes, dois valores extremos também foram identificados, sendo esses nos meses de novembro de 1982 e julho de 1983, com alturas pluviométricas de 607 e $623 \mathrm{~mm}$, respectivamente, ambos registrados na mesma anomalia de El Niño. $O$ mês mais chuvoso também foi outubro, com mediana de $238 \mathrm{~mm}$ e o mais seco foi agosto, com $99 \mathrm{~mm}$. A menor altura pluviométrica mensal foi observada em agosto de 2012, período neutralidade do ENOS.

Na estação de Pato Branco, constatou-se a maior altura pluviométrica mensal, ocorrida no mês de julho de $1983 \mathrm{com} 723 \mathrm{~mm}$. Em seguida, identificouse novembro de 1982 com $575.5 \mathrm{~mm}$, como já mencionado, ambos na mesma anomalia de El Niño. Além disso, foram observados sete valores discrepantes na 
precipitação mensal da estação. O mês mais chuvoso em Pato Branco também foi outubro com mediana de $218 \mathrm{~mm}$, porém o mais seco, diferente das demais, foi março com mediana de $122 \mathrm{~mm}$. Essa estação apresentou a maior discrepância mensal dentre as analisadas, esse fato ocorreu em julho com variação de $5 \mathrm{~mm}$ a $720 \mathrm{~mm}$ em Pato Branco.

Em Francisco Beltrão, a estação mais chuvosa da região, como já mencionado, houve apenas um valor extremo no mês de julho de 1983, com precipitação de $668 \mathrm{~mm}$. Ainda foram registrados 16 valores discrepantes na série mensal. O mês mais chuvoso foi outubro com mediana de $239 \mathrm{~mm}$ e o mais seco foi agosto com $119 \mathrm{~mm}$. A menor altura pluviométrica mensal na estação ocorreu em abril de 1978, seguido de agosto de 2012, ambos em período de neutralidade na TSM.

As maiores alturas pluviométricas anuais, mensais e diárias foram extraídas para identificar os eventos extremos de precipitação, e assim comparar com o período correspondente da TSM. Para a precipitação anual e diária foram retiradas as dez maiores alturas pluviométricas da série, enquanto para a precipitação mensal, foi retirado o maior valor registrado em cada mês (Figura 06, 07 e 08).

Para a precipitação anual (Figura 06), observou-se em Chopinzinho que das dez maiores alturas pluviométricas, seis foram em períodos de El Niño, sendo destes, os quatro anos mais chuvosos da série. Ainda houve quatro em períodos de neutralidade, e cabe destacar que nenhum dos anos mais chuvosos na estação foram observados em períodos de La Niña. 


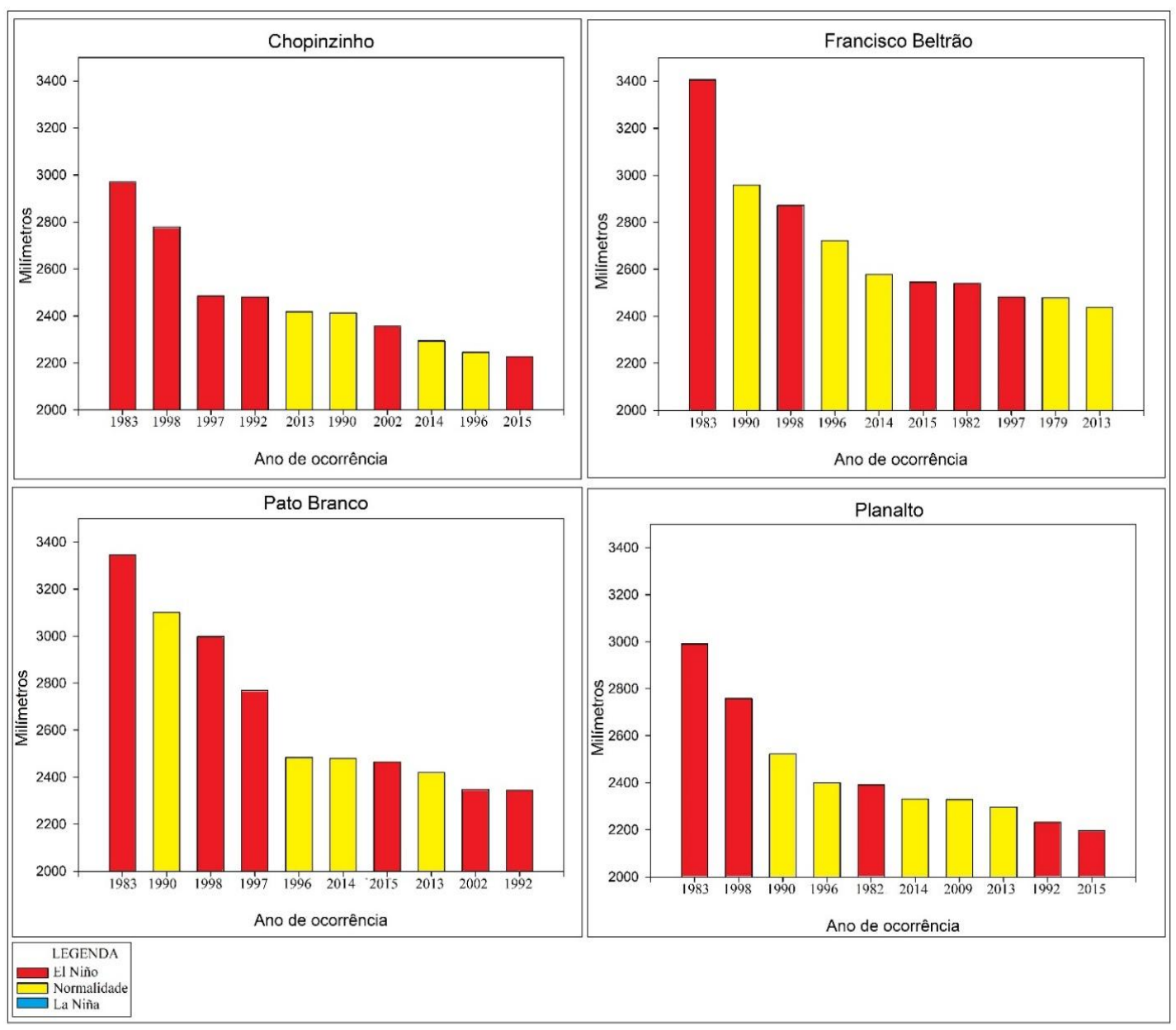

Figura 06 - Maiores alturas pluviométricas anuais na Mesorregião Sudoeste Paranaense e a comparação com El Niño-Oscilação Sul. Fonte dos dados: Águas Paraná; ANA; IAPAR e INMET (2019); NOAA/CPC (2019), organizado pelos autores (2019).

Em Pato Branco e Planalto, dos dez anos mais chuvosos, cinco foram em período de El Niño e cinco em normalidade. A mesma quantidade se repete para a estação de Francisco Beltrão, cabe-se ainda destacar que neste local e em período de El Niño ocorreu o ano mais chuvoso registrado na região, o de 1983 com 3405mm. Também nestas três estações nenhum dos dez anos mais chuvosos ocorreu em período de La Niña. Os anos de 1983, 1996, 1998, 2013, 2014 e 2015 se repetem entre os dez mais chuvosos de todas as estações analisadas.

Para a precipitação mensal (Figura 07), observou-se na estação de Chopinzinho que a maioria das precipitações mais elevadas por mês ocorreram em períodos de El Niño, incidindo em sete dos doze meses do ano e ainda sendo as sete maiores alturas pluviométricas mensais registradas. O mês de outubro, o mais chuvoso da região, registrou apenas a quinta maior precipitação mensal. A maior altura pluviométrica foi registrada em julho de 1983. Apenas o mês de fevereiro mais chuvoso ocorreu em período de anomalia de La Niña. Já em 
agosto, o mês mais seco na estação, registrou altura pluviométrica mensal máxima maior que os meses de fevereiro e março.

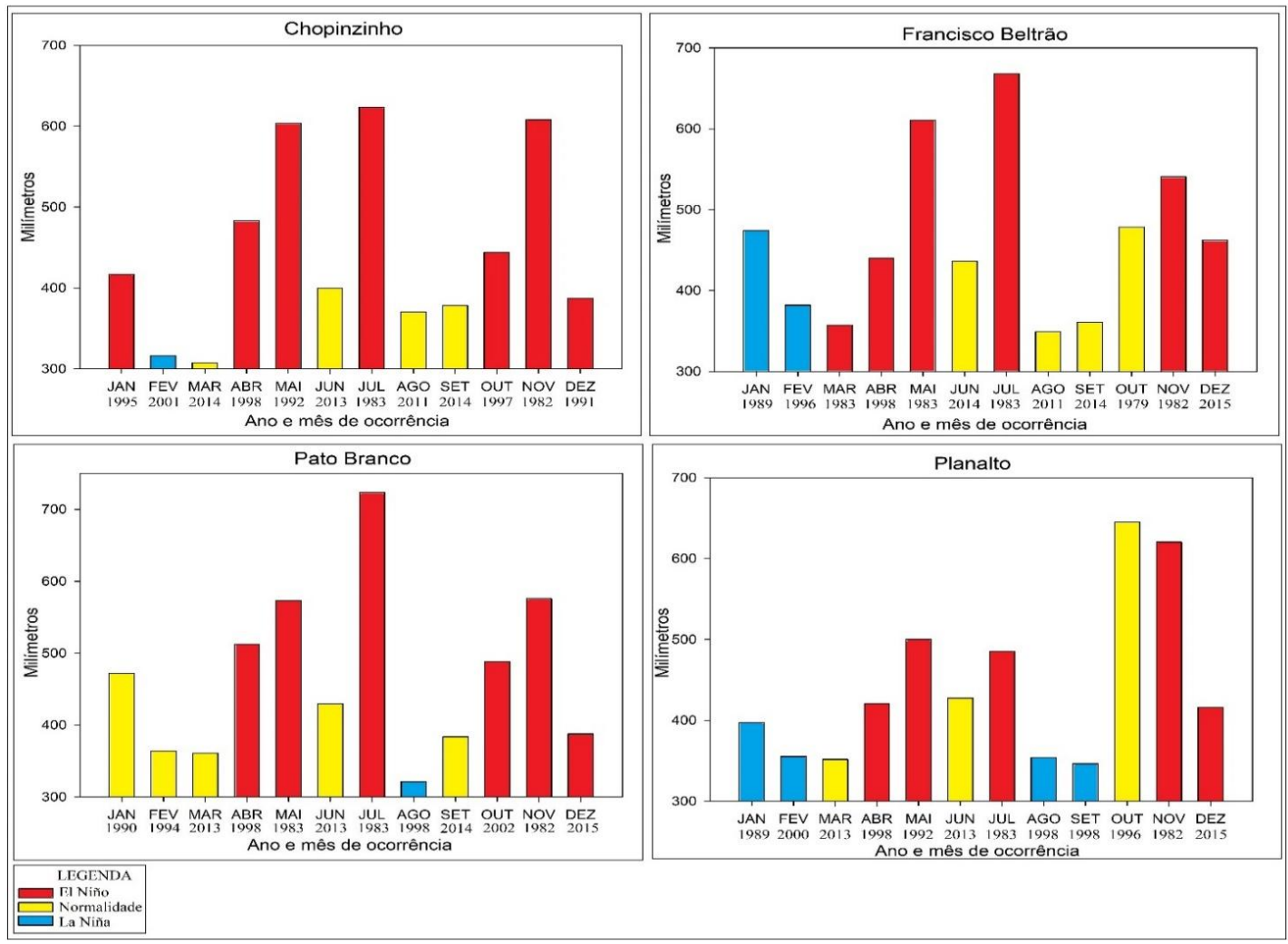

Figura 07 - Maiores alturas pluviométricas mensais na Mesorregião Sudoeste Paranaense e a comparação com El Niño-Oscilação Sul. Fonte dos dados: Águas Paraná; ANA; IAPAR e INMET (2019); NOAA/CPC (2019), organizado pelos autores (2019).

Em Francisco Beltrão observou-se, novamente, as maiores alturas pluviométricas de cada mês com predomínio de El Niño, em seis dos doze meses. Houve duas ocorrências em períodos de La Niña, nos meses de janeiro e fevereiro, e ainda cabe-se salientar que janeiro foi o único mês em período de La Niña a registrar precipitação superior a $400 \mathrm{~mm}$, dentre as quatro estações.

Em Pato Branco, também foram registradas seis das doze maiores alturas pluviométricas de cada mês em El Niño, mas, cabe destacar, que foi a estação com maior número de meses sob influência de normalidade, com cinco ocorrências. Apenas o mês de agosto, com menor altura pluviométrica máxima da estação sob influência de La Niña.

Planalto foi a única estação que a maior precipitação mensal não ocorreu em julho de 1983, sendo registrada em outubro de 1996, com 645mm, sendo em período de normalidade. Esta estação foi a que mais sofreu influência de períodos de La Niña na precipitação máxima de cada mês, com quatro ocorrências. Porém o maior número ainda ocorreu em El Niño com cinco ocorrências mensais. 
Para as maiores precipitações no intervalo de 24 horas (Figura 08), identificou-se em Chopinzinho que as cinco maiores alturas pluviométricas diárias ocorreram em período de influência da anomalia El Niño, sendo a maior registrada em 28 de maio de 1992, com 189mm. Nenhuma das precipitações diárias analisadas ocorreu em período de La Niña. Ainda cabe destacar que nenhuma das 10 maiores precipitações analisadas ocorreram no mês de outubro, o mais chuvoso na região.

A estação de Francisco Beltrão foi a única a ter sete alturas pluviométricas diárias superiores a $150 \mathrm{~mm}$, sendo cinco destas em período de $\mathrm{El}$ Niño. A maior foi registrada em 06 de junho de 1991, com 183mm. Apenas a precipitação de $152 \mathrm{~mm}$ em agosto de 2011 foi registrada em período de La Niña.

Em Pato Branco, diferente das demais, constatou-se que a segunda maior precipitação diária ocorreu em período de La Niña, com 142mm, em agosto de 2011. E ainda que seis das dez maiores precipitações diárias foram em períodos de El Niño.

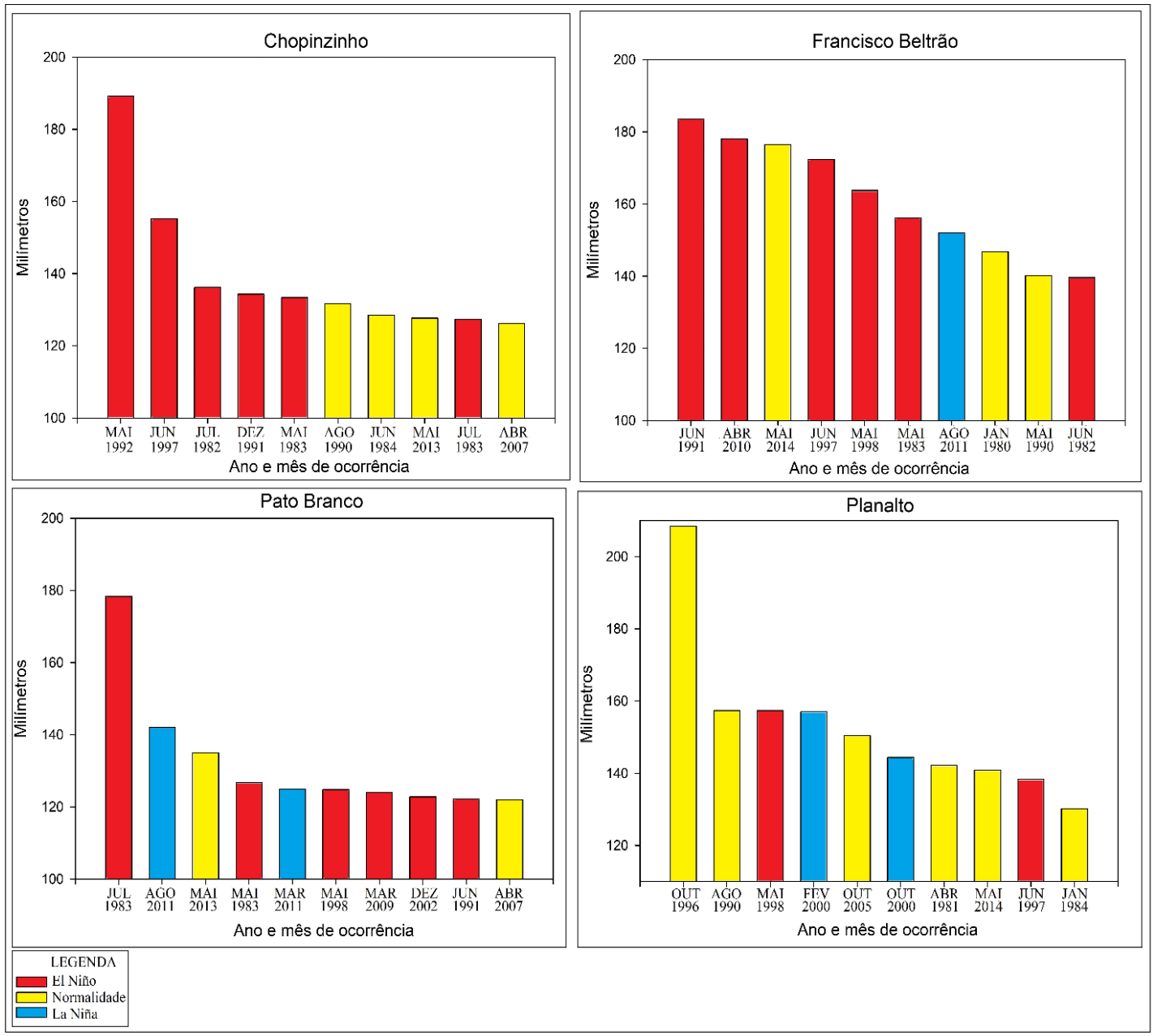

Figura 08 - Maiores alturas pluviométricas em 24 horas na Mesorregião Sudoeste Paranaense e a comparação com El Niño-Oscilação Sul Fonte dos dados: Águas Paraná; ANA; IAPAR e INMET (2019); NOAA/CPC (2019), organizado pelos autores (2019). 
Já em Planalto foi registrada a maior precipitação em 24 horas da série, mesmo sendo o local mais seco dentre as estações analisadas. O ocorrido foi em 12 de outubro de 1996, com 208mm acumulados, em período de normalidade na TSM. Ainda cabe-se destacar que diferente das demais, nesta estação as maiores alturas pluviométricas em 24 horas ocorreram em período de normalidade, constando apenas duas em período de El Niño e duas em La Niña.

\section{CONSIDERAÇÕES FINAIS}

Identificou-se que a precipitação média anual da região Sudoeste do Paraná é influenciada, principalmente pelo relevo. As regiões mais altas, próximo à divisa com Santa Catarina registraram médias de até $2170 \mathrm{~mm}$, enquanto as porções mais baixas, próximo a calha do Rio Iguaçu, registraram média de até $1920 \mathrm{~mm}$. Observou-se ainda que os maiores eventos de precipitação anual na região ocorreram em períodos de El Niño, e com menor frequência em neutralidade do ENOS. Entre as maiores precipitações anuais, nenhuma ocorreu em período de La Niña. Mesmo a MRSPR sendo a segunda região mais chuvosa do Estado do Paraná, observou-se grandes discrepâncias entre a precipitação anual e mensal, com variação máxima de $3400 \mathrm{~mm}$ no ano mais chuvoso a $1200 \mathrm{~mm}$ no ano mais seco em Francisco Beltrão, e mensal de $720 \mathrm{~mm}$ a $5 \mathrm{~mm}$ no mês de julho em Pato Branco.

Grandes precipitações pluviométricas foram identificadas em período de 24 horas na região, sendo a maior, de $208 \mathrm{~mm}$, na estação de Planalto, superior à mediana da maioria dos meses em todas as estações. A estação de Pato Branco apresentou maior frequência pluviométrica que as demais, mesmo não sendo a mais chuvosa da região, demonstrando assim maior frequência e menor intensidade pluviométrica.

Por fim, constatou-se que os eventos de maiores alturas pluviométricas na região ocorreram normalmente em períodos de El Niño ou, com menor frequência, em neutralidade, enquanto que períodos de La Niña ocorreram em boa parte dos períodos secos e em poucos eventos chuvosos extremos.

\section{REFERÊNCIAS}

AGOVINO, M. et al. Agriculture, climate change and sustainability: The case of EU-28. Ecological Indicators, https://doi.org/10.1016/j.ecolind.2018.04.064. 2018.

ALBUQUERQUE, F. da S. et al. Aptidão climática de culturas agrícolas importantes para comunidades indígenas do semiárido brasileiro. Irriga, v. 22, n. 1, p. 59, 2018.

ANDERSON, W. et al. Crop production variability in North and South America forced by life-cycles of the El Niño Southern Oscillation. Agricultural and Forest Meteorology, v. 239, p. 151-165, 2017.

AYOADE, J. O. Introdução à climatologia para os trópicos. Tradução de Maria Juraci Zani dos Santos; revisão de Suely Bastos. São Paulo: DIFEL, 1986. 
BEREZUK, A. G.; SANT'ANNA NETO, J. M. Eventos climáticos extremos no oeste paulista e norte do Paraná, nos anos de 1997, 1998 e 2001. Revista Brasileira de Climatologia, v. 2, p. 9-22, 2006.

BEREZUK, A. G. Eventos Extremos: Estudo da Chuva de Granizo de 21 de Abril de 2008 na Cidade de Maringá-PR. Revista Brasileira de Climatologia, v. 5, p. 153-164, 2017.

BERLATO, M. A. et al. Associação entre El Niño Oscilação Sul e a produtividade do milho no Estado do Rio Grande do Sul. Pesquisa Agropecuária Brasileira, v. 40, n. 5, p. 423-432, 2005.

BERLATO, M. A.; FONTANA, D. C. El Niño e a Agricultura da Região Sul do Brasil. Embrapa Trigo. 2011.

BERTILSSON, L. et al. Urban flood resilience-a multi-criteria index to integrate flood resilience into urban planning. Journal of Hydrology, https://doi.org/10.1016/j.jhydrol.2018.06.052. 2018.

CALDANA, N. F. S. et al. Ocorrência, Frequência E Impactos de Precipitações Granizo na Região Metropolitana De Curitiba. Caminhos de Geografia, 2018a. No Prelo.

Ocorrências de Alagamentos, Enxurradas e Inundações e a Variabilidade Pluviométrica na Bacia Hidrográfica do Rio Iguaçu. Revista Brasileira de Climatologia, v. 23, p. 343-355, 2018b.

CARAMORI, P. H. et al. Zoneamento agroclimático para o pessegueiro e a nectarineira no Estado do Paraná. Revista Brasileira de Fruticultura, Jaboticabal, v. 30 , n. 4 , p. $1040-1044,2008$.

CARVALHO, A. A. et al. Zoneamento agrometeorológico da moringa para o Estado de Pernambuco em condições atuais e projeções futuras. Journal of Environmental Analysis and Progress, v. 2, n. 3, p. 194-202, 2017.

CONCEIÇÃO, M. A. F. Índices hídricos climáticos para a viticultura. Pesquisa Agropecuária Brasileira, v. 53, n. 6, p. 765-768, 2018.

CONTI, J. B. Considerações sobre as mudanças climáticas globais. In: Revista do Departamento de Geografia, v. 16, p. 70-75, 2005.

DAMASCENA, A. P. et al. Zoneamento Agroclimático Para o Cultivo do Abacaxi no Espírito Santo Mediante Interpolação Espacial. Revista Univap, v. 22, n. 40, p. 327, 2017.

ELY, D. F.; DUBREUIL, V. Análise das Tendências espaço-temporais das precipitações anuais para o estado do Paraná - Brasil. Revista Brasileira de Climatologia, v. 21, p. 553-569, 2017.

FONTANA, D. C.; BERLATO, M. A. Influência do El Niño Oscilação Sul sobre a precipitação pluvial no estado do Rio Grande do Sul. Revista Brasileira de Agrometeorologia, v. 5, n. 1, p. 127-132, 1997.

GELCER, E. et al. Influence of El Niño-Southern oscillation (ENSO) on agroclimatic zoning for tomato in Mozambique. Agricultural and forest meteorology, v. 248, p. 316-328, 2018.

HOLLEMAN, I. Hail Detection Using Single-Polarization Radar. Ministerie van Verkeer en Waterstaat, Koninklijk Nederlands Meteorologisch Instituut, 2001. 
HUANG, Kangdi et al. Flood hydrograph coincidence analysis for mainstream and its tributaries. Journal of Hydrology, v. 565, p. 341-353, 2018.

IAPAR. Agrometeorologia: Cartas Climáticas. Instituto Agronômico do Paraná. Disponível em: <http://www.iapar.br/>. Acesso em: 15 de janeiro de 2019.

IBGE (Fundação Instituto Brasileiro de Geografia e Estatística), Censo Demográfico: Brasil, 2017. Rio de Janeiro: IBGE, 2018.

IPCC. Technical Summary. In: Climate Change 2013: The Physical Science Basis. Contribution of Working Group I to the Fifth Assessment Report of the Intergovernmental Panel on Climate Change. Cambridge University Press, Cambridge, United Kingdom and New York, NY, USA, 2013.

JAMALI, B. et al. A rapid urban flood inundation and damage assessment model. Journal of Hydrology, v. 564, p. 1085-1098, 2018.

KARIMI, $V$. et al Vulnerability and adaptation of livestock producers to climate variability and change. Rangeland Ecology \& Management, v. 71, n. 2, p. 175$184,2018$.

et al. Climate change and agriculture: Impacts and adaptive responses in Iran. Journal of Integrative Agriculture, v. 17, n. 1, p. 1-15, 2018.

KUNZ, M. et al. Recent trends of thunderstorm and hailstorm frequency and their relation to atmospheric characteristics in southwest Germany. International Journal of Climatology: A Journal of the Royal Meteorological Society, v. 29, n. 15, p. 2283-2297, 2009.

LEM, S. et al. The heuristic interpretation of box plots. Learning and Instruction, v. 26 , p. $22-35,2013$.

MACHADO, T. da S. et al. Zoneamento Agroclimático do Melão na Região Sudoeste de Mato Grosso. Revista Brasileira de Climatologia, v. 20, p. 169-181, 2017.

MANCILLAS, R. G. et al. Zonificación edafoclimática para el cultivo de Jatropha curcas L., en Tabasco, México. Investigaciones Geográficas, Boletín del Instituto de Geografía, v. 2015, n. 86, p. 25-37, 2015.

MARCELINO, E. V.; Desastres Naturais e Geotecnologias: Conceitos Básicos. INPE, Santa Maria, 2007.

DE MATOS, R. M. et al. Agroclimatic Potential For Mango Culture in the Municipality of Barbalha CE. Revista Brasileira de Agricultura Irrigada, v. 12, n. 1, p. 2366, 2018.

MICHLER, J. et al. Conservation agriculture and climate resilience. Journal of Environmental Economics and Management, v. 93, p. 148-169, 2018.

MUSTAFA, A. et al. Effects of Spatial Planning on Future Flood Risks in Urban Environments. Journal of Environmental Management, v. 225, p. 193-204, 2018.

NOAA/CPC - National Oceanic and Atmospheric Administration/Climate Prediction Center. Oceanic Niño Index. 2019. Disponível em:< http://www.cpc.ncep.noaa.gov/products/analysis_monitoring/ensostuff/ensoyea rs.shtml >. Acesso em 14/01/2019. 
PANDOLFO, C. et al. Zoneamento agroclimático do mirtilo irrigado em Santa Catarina. Agropecuária Catarinense, v. 30, p. 84-88, 2017.

SANCHES, F. de O., et al. Tendência de longo prazo das chuvas diárias no Sudoeste do Rio Grande do Sul: os eventos extremos e a arenização. Revista Brasileira de Geografia Física, v. 7, p. 1100-1109, n. 2014.

PAILLER, S.; TSANEVA, M. The effects of climate variability on psychological well-being in India. World Development, v. 106, p. 15-26, 2018.

PASSOS, M. L. F. Balanço hídrico climatológico e classificação climática para o município de Balsas-Ma. Scientia Agraria, v. 18, n. 1, p. 83-89, 2017.

PELL, M. C. et al. Update World Map of the Köppen - Geiger Climate Classification. Hydrology and Earth System Sciences, Munich, v. 11, n. 01, p. 1633-1644, 2007.

PUNGE $H$. J. et al. Hail frequency estimation across Europe based on a combination of overshooting top detections and the ERA-INTERIM reanalysis. Atmospheric Research, v. 198, p. 34-43, 2017.

RAO, V. B.; HADA, K. Characteristics of rainfall over Brazil: Annual variations and connections with the Southern Oscillation. Theoretical and Applied Climatology, v. 42, n. 2, p. 81-91, 1990.

DOS REIS, L. S. et al. Zoneamento agroclimático de cultivos com potencial energético no estado de Minas Gerais. Revista Espinhaço, p. 50-63, 2017.

SANCHEZ, J. L. et al. Are meteorological conditions favoring hail precipitation change in Southern Europe? Analysis of the period 1948-2015. Atmospheric Research, v. 198, p. 1-10, 2017.

SANTI, A. et al. Impacto de cenários futuros de clima no zoneamento agroclimático do trigo na região Sul do Brasil. Agrometeoros, v. 25, n. 2, p. 303-311, 2018.

SCHNEIDER, H.; DA SILVA, C. A. O uso do modelo box plot na identificação de anos-padrão secos, chuvosos e habituais na microrregião de Dourados, Mato Grosso do Sul. Revista do Departamento de Geografia, v. 27, p. 131-146, 2014.

SOMBOONSUKE, B. et al. Farmers' perceptions of impacts of climate variability on agriculture and adaptation strategies in Songkhla. Kasetsart Journal of Social Sciences, v. 39, n. 2, p. 277-283, 2018.

DE SOUSA, J. W.; DE OLIVEIRA, P. F. Risco climático para o café Conilon (Coffea canephora) nos municípios de Rio Branco, Tarauacá e Cruzeiro do Sul, AC. Revista Brasileira de Ciências da Amazônia/Brazilian Journal of Science of the Amazon, v. 7, n. 2, p. 31-40, 2018.

DE SOUZA, D. C. F. et al. Zoneamento Agroclimático da Palma Forrageira (Opuntia Sp) Para o Estado de Sergipe. Revista Brasileira de Agricultura Irrigada, v. 12, n. 1, p. 2338, 2018.

TAYT'SOHN, F. C. O. Assessing sugarcane expansion to ethanol production under climate change scenarios in Paranaíba river basin-Brazil. Biomass and Bioenergy, v. 119, p. 436-445, 2018.

TRENBERTH, K.; NATIONAL CENTER FOR ATMOSPHERIC RESEARCH STAFF (Eds). Última alteração em 02 fev 2016. "The Climate Data Guide: Niño SST 
Indices (Niño 1+2, 3, 3.4, 4; ONI and TNI)." Disponível em: https://climatedataguide.ucar.edu/climate-data/Niño-sst-indices-Niño-12-3-344-oni-and-tni. Acesso em 22/01/2019. 